\title{
新冠肺炎疫情防控期间学校教学活动的挑战与应对策略一以人 大附中丰台学校初二年级为例
}

\author{
孙雪 \\ 中国人民大学附属中学丰台学校 \\ DOI:10.32629/er.v3i3.2527
}

[摘 要] 新冠肺炎的侵袭对传统师生面对面的教育方式提出了挑战。为了保证学生 “停课不停学”, 学校在积极创建家校课堂,做好课程指引 的同时,引导学生德育并行。

[关键词] 停课不停学; 家校课堂; 课程指引；德育并行

自新型冠状病毒感染的疫情发生以来, 在以习近平同志为核心的党中 央统一领导下, 全国人民众志成城、团结奋战, 凝聚起风雨无阻、同舟共济 的精神力量。为了阻断疫情向校园蔓延, 教育部下发通知, 要求 2020 年春季 学期延期开学, 教师利用网络平台进行教学, 做到 “停课不停学”。

针对此次突发的公共危机事件, 在中国人民大学附属中学丰台学校制 定的防控疫情延迟开学实施方案的基础之上, 初二年级利用科技发展带来 的便利积极应对, 开展了一系列的教育教学活动, 主要包括课程指引、家校 课堂以及德育并行三个方面。旨在引导学生在家科学避疫的前提之下, 为 授课教师提供教学安排指导, 促进家长-教师之间的合作, 确保学生在居家 学习中温故而知新, 德育并行。

\section{1 课程指引: 温故而知新}

根据教育部和学校防疫工作的安排, 在延期开学期间, 初二年级积极 安排教学工作。主要以复习巩固为主要授课任务, 教师不讲授新课, 带领学 生回顾知识点, 为后期的学习打好基础, 保证学生温故, 然后知新; 引领学 生进行自我探究, 创造性的开展研究学习, 利用科技带来的便利, 探索未知 的世界, 增强自我研究的能力; “以人为镜可以明得失, 以史为镜可以知兴 废”, 鼓励学生阅读经典著作, 学会站在巨人的肩膀上思考问题, 在前人研 究探索的基础之上创新发展; 健康的身体是进行一切活动的前提, 要求学 生开展适当的体育锻炼, 强健体隗; 心灵就像航船, 需要灯塔的指引, 正确 的心理引导才能使得学生在抗疫阶段始终保持积极健康的心态。

为了完成以上五点的课程指引工作, 保证线上教学的顺利开展, 学生 学有所得, 初二年级在学校领导的指导之下进行了如下的工作安排:

1. 1 制定线上学习时间表。针对学生居家学习的特点, 尽量保证学生每 天学习的科目和时间相对固定, 从而有利于培养学生的习惯意识。利用网 络平台开展线上教学工作只是 “停课不停学” 的形式之一, 年级鼓励各学 科教师针对学科特点, 制定复习方案、探究性学习学案, 帮助学生复习巩固 知识, 在固定的时间辅导学生进行自主学习。避免学生的 “问题性移动社 交媒体使用” 的现象 ${ }^{[1]}$ 的产生, 从而导致学习成绩下降, 家庭冲突, 甚至导 致较严重的抑郁、焦虑的孤独症状。

1.2 重视经典阅读与书写。在此特殊期间, 初二年级的语文组、数学组、 英语组、历史组、生物组结合学科特点, 开展了一系列的经典阅读活动, 让学生能够在知识的海洋中畅游。阅读书目包括《钢铁是怎样炼成的》、 《水汻传》、《傅雷家书》、《三体》、《多维阅读》、《自私的基因》、《埃博拉・血 疫》、《天朝的崩溃》等一系列文学或科学作品, 帮助学生在感受文字带来 的美好的同时, 进一步领略了学科魅力, 培养学生的主动学习兴趣。

1. 3 提倡体育锻炼。适当的体育锻炼有助于学生的身体健康, 能够帮助 学生有一个良好的精神面貌。在学校的统一安排下, 由体育老师带队创编
体能操, 录制体育教学视频, 带领学生每天进行一小时的体育锻炼, 鼓励学 生适当开展室内体育活动, 从而确保学生虽居家而不怠惰。

1. 4 注重综合素质培养。年级组为学生每天设有 50 分钟的 “自由时间 段”, 在此时间段分别加入了音乐、美术、信息、劳技、形体等科目的自 由鉴赏栏目, 确保学科内容的丰富多样性, 培养学生的兴趣点, 提高综合素 质。与此同时, 年级还为学生安排了每周一次的心理健康知识普及, 帮助学 生在疫情期间克服焦虑, 管理情绪, 保持健康乐观的心理状态。

课程指引工作并非是一人之功, 而是整个年级组教师经过多次讨论, 反复研究, 并积极与学生在课后交流心得, 及时修改调整教学模式, 于反馈 中摸索前进的成果。寓教于学, 面对这次疫情的挑战, 与学生一起成长。

\section{2 家校课堂: 新的尝试}

学习不仅局限于书本, 教育不仅局限于上课。由于新冠病毒的侵袭, 家长与老师的角色发生了转变, 以往的教学课堂是在学校中, 学生大部分 的时间都是与老师同学在一起; 但在此次疫情带来的特殊时段, 家长成为 了孩子们可以面对面接触到的 “第一手教师”。这种转变除了对教师授课 提出了挑战, 也对家长们的教育方式吹响了号角。

初二年级的学生目前大多处于叛逆期, 对家长的教育方式、理念存在 很大的怀疑和 “不屑”, 这一点也为在此期间临时担任 “教师”一职的家 长们出了难题。如何与孩子沟通? 如何了解孩子们的内心世界? 如何辅导 好孩子? 如何与任课教师沟通? 等问题如同 “十万个如何”一样都出现在 家长们的脑海中。为了能够在教育的战线上打赢这场战 “疫”, 初二年级 组的所有教师积极与家长进行沟通。确定孩子在家的教学-辅导方式, 为孩 子营造健康、良好的学习环境。每日与班主任、家长反馈孩子当日学情, 并对优秀同学进行表扬, 通过榜样带动力量, 促进整个班、整个年级的学风 发展, 以此推动教师与家长互换角色体验, 达到协助共进, 确保孩子学习不 落队, 稳中有进。同时也是为初三年级的到来做好准备。因此, 我们鼓励家 长和教师一起开展高质量的教育尝试, 与孩子共建美好回忆, 主要的措施 如下:

2. 1 家长是孩子们的第一任教师, 要了解孩子的内心世界, 增加彼此之 间的了 解 ${ }^{[2]}$ 。疫情的到来, 虽然阻断了家长外出工作的脚步, 但是也为平日 里忙碌的家长们提供了一个与孩子们进行高质量的亲子活动的机会, 例如 与孩子一起读一本书, 交流心得; 整理照片, 回顾家庭故事; 一起看几部高 质量的亲子电影; 鼓励家庭故事会; 学习厨艺; 组织家务安排等各种形式 的活动。通过此类简单可行的亲子活动, 在交流中深化家长和孩子对彼此 的了解, 同时加深孩子对于生活、社会、文化的感悟, 体会家庭教育的美妙 与温暖。

2.2教师, 要努力成为家长的模范。“术业有专攻”, 并不是每一位家长 
都能胜任教师的职业, 教师应当主动积极地鼓励、引导家长高效地陪伴孩 子在家的学习和生活。帮助孩子利用居家的这段时间, 合理安排自己的学 习和休息, 培养孩子们的时间管理和自主学习的能力, 转换学习状态, 变 “被动” 为 “主动”, 做自己学习生活的主人。

2. 3兴趣是最好的老师。以往孩子们的生活基本都在学校, 无暇过多涉 及孩子自身的兴趣爱好, 教师应当鼓励家长细心观察孩子的兴趣爱好, 并 积极引导, 为孩子多方面发展提供精神和物质方面的支持, 发挥家庭成员 的相互促进作用, 利用这段时间, 培养一项孩子受益终生的习惯或兴趣爱 好, 成为全面发展的新时代人才。

2. 4培养孩子的忧患意识, 科学避疫。引导孩子了解疫情到来时, 各领 域人员的工作情况, 可以通过自主搜集疫情信息、整理疫情数据、分析疫 情产生的原因、预测疫情产生的社会影响等。从而鼓励学生亲身参与, 帮 助学生了解社会运作、科学防疫、社会经济文化等各方面的知识。培养学 生的社会责任感及逻辑思维, 引导学生树立健康观念及忧患意识。引导孩 子关注疫情进展, 了解野生动物保护、病毒知识、防控知识等, 拓展孩子的 视野和知识面, 更好地去理解现实社会, 帮助树立科学思维观念, 运用科学 逻辑分析、解决问题。在疫情期间, 学校鼓励充分发挥家庭教育的作用, 让家长和孩子们一同关注家庭对社会的贡献, 关注社会发展进程, 加深对 生命的理解和生活的认知。

通过以上四点的家校合作, 在科学避疫的同时, 加深家长和孩子的感情, 做到互相理解。并在此基础上, 开展教师引导, 教师-家长角色互换, 增强教 师-家长-学生三者之间关系的变化, 为后期家校合作奠定坚实的基础。

\section{3 德育并行：做有责任心的接班人}

在德育方面, 初二年级借此契机, 以活动为教和学的基本形式 ${ }^{[3]}$, 开展 了 “凝聚力量、同心抗疫” 的主题教育活动, 指导学生坚定信心、科学抗 疫, 培养学生的家国情怀和社会责任感。在本系列主题班会活动中, 初二年 级在各班班主任的带领下, 精心准备, 以别样的方式向抗疫英雄们致敬, 展 现自己的社会担当。本文选取初二年级 6 个班中较为突出的主题活动进行 展示, 以此来体现学生作为新时代接班人的信心、责任心以及爱心。

所谓知已知彼, 方能百战不殆。为了能够更好地了解新冠肺炎的来龙 去脉, 初二 1 班通过小组专题合作的方式, 分别对新冠病毒的来源, 传播途 径以及个人防护三个方面进行了科普研究。通过此次活动, 不仅对新冠病 毒有了更好的了解, 学生还通过专题合作, 增强了协作能力。除此之外, 学 生还进行了疫情期间家务大比拼, 家校引领, 开展德育工作。

抗疫的路上你并不孤独。初二 2 班通过观看新冠病毒纪录片和 “武汉 来信” 系列视频, 在了解疫情的发展情况的同时感受武汉现状。虽然孩子 们还不能上前线与抗疫英雄们并肩作战, 但是学生们以回信的形式, 向处 于抗疫前线的英雄们表达敬意及祝福, 告诉他们, 你们并不孤独, 我们与你 们在一起。

扬帆起航需要一致的步伐和认知。为了让学生能够体会医者之心, 初 二 3 班依托阅读名著《水吘传》鲁智深的佛心, 引导学生与抗击疫情主战场 同舟共济, 坚定理想信念, 培育爱党爱国爱人民的家国情怀。
稳定的后方是战疫胜利的前提。不信谣，不传谣，坚信中华民族的伟 大。初二4班从 “疫情下我们的生活” 出发, 结合实际, 探讨了这段特殊时 期学生的生活以及抗疫英雄们的生活。通过此次活动, 一方面, 帮助学生坚 定信心, 合理安排时间自主学习; 另一方面, 引导学生崇尚科学, 致敬英雄。

人类需要大自然, 但大自然, 并不一定需要人类。作为人类的母亲, 大 自然给予了人类太多, 而人类却只懂得索取。初二 5 班以 “保护环境, 关爱 野生动物”为主题, 引导学生思考疫情与野生动物的关系, 进一步探讨人与 自然的相处模式。并通过手抄报的形式, 呼吁大家保护野生动物, 实现人与 自然的和谐共处, 让更多的人明白人类离不开大自然。

哪有什么岁月静好, 只不过是有人在替我们负重前行。初二6班以致敬 疫情最美 “逆行者” 为主题, 深入了解到身处不同岗位的逆行者们在艰难 险阻面前勇挑重任的光辉事迹, 讲述 “平凡而又伟大” 的暖心故事, 分享和 传递爱心。

“疫情无情人有情”, 通过这一系列的活动, 学生更好地明白了家国情 怀, 明确了我们与未来的关系; 更好地敬畏自然, 认识我们与灾难的关系。 与此同时, 学生在学习的同时, 德育并行, 在灾难中提升自我, 升华品德。

\section{4 启示: 新模式的探索}

此次疫情对于传统的学校教育是一次挑战, 同时也是一个机遇。如何 转劣势为优势, 使学生在此期间得以成长发展才是教师和家长需要关注的 主要任务。在本次防控疫情, 延期开学的过程中, 我们认识到要区分线上学 习与在校学习的区别, 做到了不照搬照抄学校时间表, 灵活安排学习时间, 充分鼓励学生自主学习、探索实践。通过课程引导各科教师的辅导安排, 开创新型的家校合作模式, 为学生的学习成长保驾护航。与此同时, 关注学 生的心理发展, 促进德育并行。

我们知道, 社会是最好的课堂。此次众志成城、举国抗疫的过程, 本身 就对学生具有丰富的教育意义。“停课不停学”, 对同学们来说不仅仅是单 纯的网上学习, 学校可以借此机会帮助学生去认识生命的意义、科学的价 值、健康的重要等等, 通过引导学生自主阅读、自主锻炼、自主劳动、自 主探究, 实现更有价值的自主成长。

本文以中国人民大学附属中学丰台学校初二年级在面对公共危机事 件中的教育反思与应对工作为出发点, 积极探索, 愿能抛砖引玉, 一起探讨 防控疫情期间的教育核心和重点。

\section{[参考文献]}

[1]姜永志,白晓丽.青少年问题性移动社交媒体使用的教育引导 [J]. 教育科学研究,2019(6):65-70.

[2]马元英,焦玉峰.建立良好亲子关系的几点思考[J].中小学心理健康 教育,2019(19):74-75.

[3]俞微微.不一样的体验:道德与法治课堂 “微剧场” 创新实践 [J].中 小学德育,2020(2):43-45.

\section{作者简介:}

孙雪(1992--), 女, 汉族, 北京人, 硕士研究生, 中学二级教师, 从事英 语教学研究。 